\title{
Prospective Study
}

\section{e Pupillometry: The Influence of Gender and Anxiety on the Pain Response}

Adriana L. Bertrand, MSC, João Batista Santos Garcia, PhD, Erica B. Viera, MsC, Alcione M. Santos, PhD, and Romero H. Bertrand MSc

From: Federal University of Maranhão, São Luis, Maranhão Brazil

Address correspondence: João Batista Santos Garcia, PhD Department of Anesthesia, Pain and Palliative Care Federal University of Maranhão Ave. São Marcos, no. 4, quadra C Apt. 502 Ponta da Areia. São Luis, Maranhão Brazil E-mail: jbgarcia@uol.com.br

Disclaimer: There was no external funding in the preparation of this manuscript.

Conflict of interest: None.

Manuscript received: 01-20-2013 Revised manuscript received: 02-23-2013

Accepted for publication: 02-28-2013

Free full manuscript: www.painphysicianjournal.com
Background: Studies suggest that the pain response may be evaluated using pupillometry and is influenced by factors such as gender and anxiety.

Objectives: The aim of this study was to use pupillometry to observe the effects of gender and anxiety on the pain response.

Study Design: A randomized, prospective, clinical and interventional study.

Setting: Center for Research on Pain at the Federal University of Maranhão, Brazil.

Methods: Ninety-six patients were divided into groups according to their level of anxiety as indicated by the Beck questionnaire. Under photopic conditions and using retinography, these patients underwent pupillometry while a painful pressure stimulus of 1,500 $\mathrm{kPa}$ was applied to the middle phalanx of each patient's right middle finger using a pressure algometer.

Results: The pupil diameter increased in response to pain in all study participants, regardless of gender and anxiety level; the average pupil diameter was $3.265 \pm 0.028 \mathrm{~mm}$ before the painful stimulus and $4.31 \pm 0.200 \mathrm{~mm}$ for the duration of the stimulus $(P=0.0251)$. There was no significant difference between the genders in the level of anxiety $(P=0.614)$. Regardless of gender, individuals with moderate to severe anxiety had higher average pupil diameters than individuals exhibiting mild or no anxiety $(P=0.019)$. Men had a higher average pupil diameter than women $(4.53 \pm 0.345 \mathrm{~mm}$ and $4.48 \pm 0.358 \mathrm{~mm}$, respectively); however, this difference was not statistically significant in the presence of moderate to severe anxiety $(P=0.072)$.

Limitations: The number of men with high anxiety was insufficient to create their own group.

Conclusions: The pupil dilation in response to a painful stimulus was similar in both genders. Additionally, regardless of gender, the average pupil diameter was greater in the presence of moderate to severe anxiety.

Key words: Pupillometry, pain, gender, anxiety

Pain Physician 2013; 16:-E257-E266 $n$ the 1990s, research efforts focused on detailing and explaining the relationship between the pupil and the autonomic nervous system were intensified, and the quest to develop methods for monitoring the activity of the sympathetic and parasympathetic nervous systems began (1). Many of these methods relied upon monitoring changes in pupil dynamics (2-4).

Manual pupillometers $(5,6)$, corneal topographs
$(7,8)$, and infrared systems (7,9-11) have been developed and used to measure the pupil diameter and the pupillary response to various factors and stimuli, such as nociceptive stimuli.

For decades, various types of painful stimuli have been used as tools to study the autonomic nervous system. These stimuli differ in their mode of presentation (acute or chronic (12-16) and origin (clinical or experi- 
mental (17-21). Various experimental approaches have been used, including pressure $(18,19)$, thermal $(18,22$ 25) and electrical (26) stimuli, ischemia induction (27), and mechanical stimulation (28).

A literature review by Grenspan et al (29) showed the differences between these techniques, discussed their clinical applications, and suggested that the gender differences were greatest in response to a painful pressure stimulus.

Although some studies did not find any gender differences in the pain response $(22,27,30)$, most have reported that women have a lower pain tolerance and a lower threshold of sensitivity to pain than men $(19,21,31-33)$.

Women have shown a greater response to pain than men in experimental studies $(17,34)$ and clinical trials $(12,15,23,35,36)$. The same pattern is observed when comparing chronic $(15,16,37)$ and acute pain $(14,38)$, with a greater prevalence in the latter.

Several hypotheses were developed to explain these findings, such as gender differences in physical $(23,27,31,33,34,39)$, hormonal (40-43), and sociocultural and emotional attributes $(37,44-49)$. Anxiety is an emotional attribute that has been shown to play an important role in the modulation of the nociceptive response $(24,44,48,50-52)$.

There are many arguments and some controversies about the ways in which anxiety can affect pain in individuals, particularly regarding how it affects different genders $(13,26,32,33)$. Although most studies report that anxiety is more prevalent in women, men seem to be more affected $(45,53)$ by positive experiences than women and women tend to be more affected by negative experiences $(37,44,54)$.

Although large international studies have been performed, there are few studies on the pain response in Latin American populations, including the Brazilian population. Whereas most studies investigate gender differences subjectively $(27,35,55,56)$ by means of several pain scales that have been validated over time, few studies have evaluated gender differences using objective measures, such as pupillometry (17). This deficiency in the field led to the development of the present study, which aims to analyze the influence of gender and anxiety on the pupillary response to pain.

\section{Methods}

With approval from the Institutional Research Ethics Committee, an experimental study of patients of both genders between the ages of 18 and 60 years was conducted from August 2009 to August 2010. The study was conducted in an outpatient clinic that specialized in ophthalmology. The patients were conscious and had intact cognitive abilities.

The necessary sample size to achieve $80 \%$ power (probability) and a type I error of $5 \%$ was calculated assuming an estimated pupil difference of $0.5 \mathrm{~mm}$ $(2,17,57,58)$ with a standard deviation of 0.5 . This calculation resulted in a sample size of 16 individuals per group, or 96 individuals in total.

The participants voluntarily agreed participate in the study after signing an informed consent form and all included were patients who sought the clinic with various types of ocular complaints.

Prospective patients were excluded based on the presence of the following criteria:

a) smoking (individuals who smoke any amount of tobacco on a daily basis);

b) alcohol use (consumption of any amount of alcoholic beverages of any kind, including sporadic consumption);

c) diabetes (patients with a blood glucose level higher than $126 \mathrm{mg} / \mathrm{dL}$ on 3 repeated samples or using medicine specific for diabetes);

d) hypertension (blood pressure higher than 135/85 $\mathrm{mmHg}$ on 2 consecutive measurements, having been diagnosed with the condition by a specialist, or using anti-hypertensive medication);

e) pregnancy (positive $\beta$-hCG test), current menstruation, dysmenorrhea, or menopause symptoms (climateric) without hormone replacement;

f) migraine (having been diagnosed by a physician or neurologist or having frequent headaches without a known cause);

g) epilepsy (reported by the patient or having been diagnosed by a neurologist);

h) psychiatric or neurologic disorders, such as Alzheimer's, Parkinson's disease, panic disorder, obsessive-compulsive disorder, depression, stroke, traumatic brain injury, and central nervous system tumors, as reported by the patient and family members or evidenced by medical reports;

i) chronic pain (pain that lasted for more than 6 months) or analgesic use (determined from a careful history of medications used by each patient, including teas and herbs, along with their active ingredients);

j) prior history of severe acute pain (identified by taking a careful medical history and comparing it with an analog pain scale); 
k) presence of skin lesions on the right arm (determined by a thorough inspection of the limb by the investigator using ectoscopy); and

I) presence of ophthalmologic disorders, such as glaucoma, dry eyes, retinal disease, or prior history of intraocular surgery (determined from an eye examination performed by the investigator). Ametropic conditions that could not be corrected to achieve $20 / 20$ visual acuity according to the Snellen eye chart in both eyes (57) were also considered to be ophthalmic disorders.

These variables could affect the patient's response to the pain stimulus, thereby invalidating the data obtained $(2,59-65)$.

Some studies suggest that simply having a prior history of acute pain can lead to such a high level of anxiety that it would cause a discharge of epinephrine and a consequent increase in pain sensitivity $(14,26,48,66,67)$; therefore, it was necessary to exclude these individuals from the study at the time of selection.

Patients with any level of anxiety who had been previously diagnosed with a psychological or psychiatric disorder and/or other associated conditions were not included in the study.

Personal data such as skin color, education level, and age were collected. The patients were divided into 4 groups according to age: 1) 18 to 30 years, 2) 31 to 40 years, 3) 41 to 50 years, and 4) over 51 years. Some studies suggested that individual factors such as age, skin color, and level of education could affect pain perception of individuals $(39,46,62)$.

Anthropometric data, including weight and height, were also collected to calculate each patient's body mass index (BMI) as well as the diameter of the middle phalanx of the middle finger of the right hand. As the painful stimulus was standard for all patients it became important to analyze whether these physical structures could interfere directly in the perception of the stimulus.

Using the BMI data, the patients were divided into the following 4 groups: 1) below $\left.18.5 \mathrm{~kg} / \mathrm{m}^{2}, 2\right) 18.5$ to $24.9 \mathrm{~kg} / \mathrm{m}^{2}$, 3) 25 and $29.9 \mathrm{~kg} / \mathrm{m}^{2}$, and 4) over $30 \mathrm{~kg} / \mathrm{m}^{2}$, following the World Health Organization (WHO) guidelines for evaluating nutritional status (69).

After the classification of the subjects, an eye exam was performed, which consisted of a visual acuity measurement, pupil measurement at rest, tear film evaluation, slit lamp biomicroscopy of the anterior segment, binocular indirect ophthalmoscopy, and applanation tonometry (70).
The visual acuity was measured using the Snellen optotype chart (68) with optimal correction. Two tests were used for the tear film evaluation: the tear film breakup time (BUT) test (71) and the Schimmer test (72) using anesthetic eye drops (Anestalcon $®$ ). The pupil diameter was assessed using a retinographer and measured in a dynamic fashion as the average diameter of the longest pupillary axis during a 15-second interval under photopic conditions. Ophthalmoscopy was performed using a binocular indirect ophthalmoscope following pupil dilation (73).

To evaluate the anterior segment of the eye, a slit lamp was carefully used (74) to look for changes that could interfere with the patient's eyesight, especially characteristic iris changes.

The photomotor reflex of the pupil was tested directly and bilaterally using a standard light source, e.g., a flashlight (75). Tonometry, which is a procedure used to measure the intraocular pressure, was performed using a Goldmann applanation tonometer (30).

Following the eye exam, patients without any disorders that met the inclusion criteria and were chosen by chance were asked to answer a questionnaire to assess their level of anxiety according to the Beck Anxiety Inventory.

The Beck Anxiety Inventory has a maximum score of 63 and establishes several categories of anxiety: a score of $0-7$ indicates a minimum level of anxiety, a score of 8-15 indicates mild anxiety, a score of $16-25$ indicates moderate anxiety, and a score of $26-63$ indicates severe anxiety.

Following the completion of the questionnaire, the patients were divided into 6 groups: M1 - males with no anxiety, M2 - males with mild anxiety, M3 males with moderate to severe anxiety, F1 - females with no anxiety, F2 - females with mild anxiety, and F3 - females with moderate to severe anxiety. The first 16 individuals of each group were included for a total of 96 participants.

Patients were then subjected to the pupillometry test, which was conducted in a closed room under photopic conditions (4 lux), with a single light source provided by the retinoscope of a retinographer (OPTO, model ADS $1.5 \mathrm{FA} /$ Color/ICG) and a camera attached to a computer. External stimuli, such as foot traffic, sounds, and odors, were controlled during the pupillometry. The patient remained seated during the test, with the chin and forehead properly positioned on the device. The exam was conducted at a fixed distance of $33 \mathrm{~cm}$ from the right eye. 
Because the device can only measure one eye per exam, the right eye was chosen to standardize the exam for all participants. The pupillary reflex to light is simultaneous (bilateral and symmetrical when a strong stimulus is used $[9,57,76-78])$, so the left eye was not evaluated.

With the arm and forearm resting on a flat surface parallel to the body, a painful pressure stimulus was applied to the dorsal surface of the middle phalanx of the right middle finger using a digital pressure algometer (model FDI, Wagner Instruments) that had a certificate of origin for metrological measurements. A controlled standard intensity was used for all patients.

When the algometer was pressed against the skin, the device instantly triggered a numerical response that was recorded as the digital value. When the pressure stimulus reached a high intensity (17), equivalent to $1,500 \mathrm{kPa}$ (corresponding to $75 \mathrm{~kg}$ applied to a surface of $0.5 \mathrm{~cm}$ in diameter, according to IPEM - SP data), the device was held in place for 20 seconds. The patient remained in the retinographer for another 20 seconds for pupil observation after the stimulus ceased, after which the exam was concluded.

The time that the patients remained in the device during the exam was divided into 3 intervals: T0 (before the painful stimulus) lasted from 0 to 40 seconds, T1

Table 1. Social demographic data of sample.

\begin{tabular}{|l|c|c|}
\hline Variables & n & \% \\
\hline Gender & 48 & 50 \\
\hline Male & 48 & 50 \\
\hline Female & 67 & 69.8 \\
\hline Age (Years) & 29 & 30.2 \\
\hline $21-40$ & 17 & 17.8 \\
\hline $41-60$ & 64 & 66.6 \\
\hline Skin color & 15 & 15.6 \\
\hline White & \\
\hline Brown & 90 & 93.7 \\
\hline Black & 6 & 6.3 \\
\hline Study (Years) & \multicolumn{1}{|l}{} \\
\hline$<12$ & 6 & 6.3 \\
\hline$>12$ & 54 & 56.2 \\
\hline BMI (kg/m2) & 32 & 33.3 \\
\hline$<18.5$ & 4 & 4.2 \\
\hline $18.5-24.9$ &
\end{tabular}

(during the painful stimulus) lasted from 40 to $60 \mathrm{sec}-$ onds, and T2 (time spent in the device after the painful stimulus ceased) lasted from 60 to 100 seconds.

The following parameters were recorded: pupil diameter (recorded every 5 seconds throughout the exam), initial pupil diameter, dilation start time, maximum dilation achieved, and time to return to baseline. The pupil diameter was measured in millimeters, and the greatest diameter within the observation period was taken as the value for each patient.

The normal distribution of quantitative variables was evaluated according to the Shapiro-Wilk test. When a variable had a non-parametric distribution, a logarithmic scale was used to achieve normality.

The qualitative and quantitative variables were compared between different groups using Fisher's exact test.

A paired Student's t-test was used to compare the average pupil diameters of each group from before and after the intervention with the average pupil diameters of each group during the application of the painful stimulus.

The comparison between different pupil diameter curves from independent groups was performed using Hotelling's test, which evaluated the equality of the mean vectors of paired measurements from multivariate populations.

The significance level was set at $P<0.05$ for all statistical tests. The data were analyzed using the Stata 10.0 program.

\section{Results}

The study evaluated 96 individuals of both genders who were divided into 6 groups according to anxiety level and gender as previously described.

Social-demographic data of sample can be seen in Table 1. The diameter of the middle phalanx of the middle finger of the right hand of the men and women was $6.1 \pm 0.29 \mathrm{~cm}$ and $5.5 \pm 0.32 \mathrm{~cm}$, respectively; the difference in diameter was statistically significant $(P=$ 0.0347).

During pupillometry, the pupil diameters increased in response to the pain stimulus in all groups, regardless of the presence or absence of anxiety; the average pupil diameter was $3.265 \pm 0.028 \mathrm{~mm}$ before the pain stimulus and $4.31 \pm 0.200 \mathrm{~mm}$ during the pain stimulus ( $P=0.0251$ ) (Fig. 1).

Men and women with moderate or severe anxiety showed greater pupil dilation than men and women 


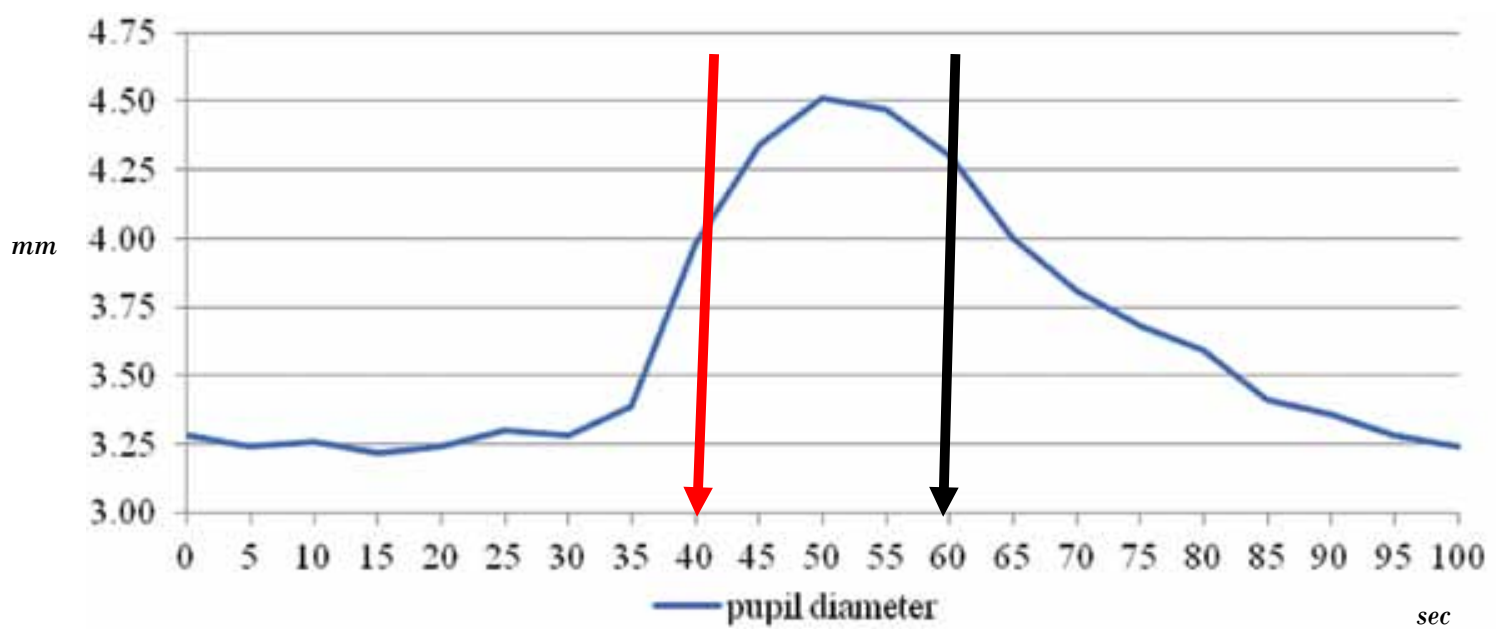

Fig. 1. Distribution of the pupil diameter average of all patients undergoing painful stimulus pupillometry and expressed in mm over time of 100 seconds. X Axis: represents pupil diameter in mm. Y axis: time in seconds. Mean pupillary diameter before, during and after the painful stimulus, were respectively: $3.265 \pm 0.028 \mathrm{~mm}, 4.285 \pm 0.200 \mathrm{~mm}$, and $3.548 \mathrm{~mm}+0.108 \mathrm{~mm}$. The pupil diameter average in the presence of painful stimuli showed a statistical difference of the averages of the other times. $(P=$ 0.0251). The red arrow points to the start of the painful stimulus and the black arrow when the stimulus was terminated.

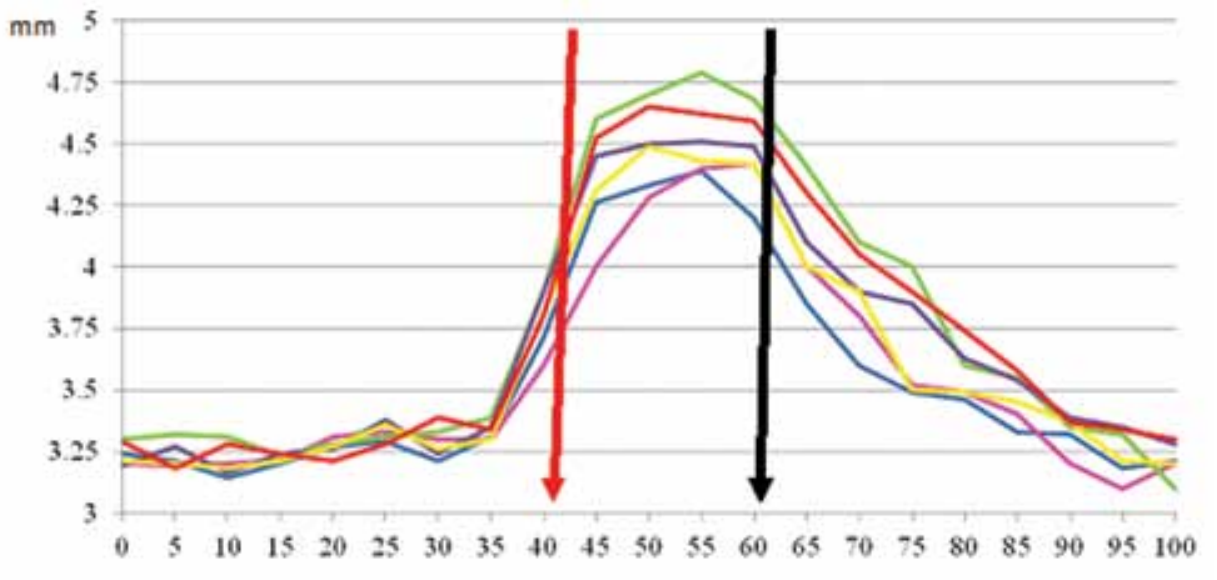

$-\mathrm{MI}_{1}-\mathrm{M}_{2}-\mathrm{M}_{3}-\mathrm{W}_{1}-\mathrm{W}_{2}-\mathrm{W}_{3} \quad$ sec

Fig 2. Distribution of the pupil diameter average of individuals of both sexes who underwent pupillometry and the painful stimulus according to the degree of anxiety. M1- Man without anxiety, M2-Man with mild anxiety, M3 - man with moderate and high anxiety, and W1- women without anxiety, W2 - woman with mild anxiety, W3 - woman with moderate and high anxiety. The red arrow points to the start of the painful stimulus and the black arrow when the stimulus was terminated. In the presence of painful stimuli there was no statistically significant difference between sexes $(P=0.614)$.

with mild or no anxiety, with averages of $4.53 \pm 0.345$ $\mathrm{mm}$ and $4.48 \pm 0.358 \mathrm{~mm}(P=0.019)$, respectively. The average pupil dilation was higher in men than in women, but this difference was not statistically significant ( $P$ $=0.072$ ) (Fig. 2).
In both the absence and the presence of any level of anxiety, the pupillary response to pain was similar in both genders $(P=0.614)$ for all groups; there was an increased pupil diameter in the presence of pain when compared to the other time intervals examined (i.e., 
before and after intervention) and the group M1 compared with M3 and W3 in the period after stimulus $(P=$ 0.042). (Table 2).

\section{Discussion}

This study found that pupil dilation is an objective marker of the pain response, which is similar in men and women, and pupil changes are exacerbated in the presence of anxiety. These findings show that anxiety affects the nociceptive response of the individual.

A retinographer was chosen as the tool to measure the pupil diameters because its measurements have been correlated with those obtained by videokeratography and infrared devices, which are considered to be the gold standard for this measurement. Studies have reported a variation of $\leq 0.05 \mathrm{~mm}$ between retinography and infrared measurements $(3,79,80)$. Due to the high cost of the infrared equipment $(39,46)$ and availability of retinographer, associated with the fact of the objective of this study was to observe a response that was greater than this variation, the use of retinography was justified. There are no published studies that compare the use of infrared equipment with retinographer in assessing pain through pupillometry as performed in this study model. There is the need for further studies in this specific field.

The diameter of the pupil was measured under photopic conditions at $33 \mathrm{~cm}$ from the eye; under these conditions, the light stimulus, accommodation reflex, convergence, and miosis would all cause the pupil to constrict $(59,61,65,75,77,81,82)$, which means that any observed pupil dilation, such as that shown in this study, would be a result of the pain stimulus alone.

A study performed by Ellermeier and Westphal (17) to evaluate the pupillary response to pain in individuals of both genders found that, according to analog pain scales, a pressure stimulus of 1,500 kPa was considered to represent a high intensity of pain. In that study, the pain stimulus was applied to the middle finger of the right hand; this nociceptive model was reproduced in the present study.

Many studies have used models of chronic $(12,13,15)$ and acute pain in clinical $(38)$ and experimental $(17,32,34)$ settings. In a retrospective analysis $(19,23)$, both types of study were shown to be effective for the evaluation of variables related to pain, although clinical studies of pain have a higher chance of bias.

During the period before the application of the pain stimulus, the average pupil diameter of all individuals, regardless of gender, was $3.26( \pm 0.028) \mathrm{mm}$. This value is similar to those reported by other studies that were also conducted under photopic conditions and that found average pupil diameters ranging from $3.03 \mathrm{~mm}$ to $3.8 \mathrm{~mm}(17,58)$. The average obtained in this study is slightly lower than the value found by Yang (65) $(4.06 \pm 0.7 \mathrm{~mm})$; however, the increased brightness level in this study may have led to more intense miosis, thereby generating a lower average.

During the period when the nociceptive stimulus was maintained, the pupil diameters of all study participants increased relative to the other times observed. This finding leads us to conclude that pupil dilation is a direct response to the activation of the autonomic nervous system via sympathetic pathways, and therefore, the pupil diameter is an objective measure of the activity and functionality of this system. In addition, the pupil diameter can be used to monitor the variability within individuals $(3,9)$, in that it can be used for selfcomparisons at different time points.

Other studies corroborate these findings because

Table 2. Distribution of the pupillary diameter average before, during, and after painful stimulus.

\begin{tabular}{|c|c|c|c|}
\hline \multirow{2}{*}{ Groups } & Before & During & After \\
\cline { 2 - 4 } & $3.23( \pm 0.055)^{\star}$ & $4.00( \pm 0.103)$ & $3.43( \pm 0.221)^{\star} \Delta$ \\
\hline M1 & $3.25( \pm 0.059)^{\star}$ & $4.14( \pm 0.345)$ & $3.46( \pm 0.311)^{\star}$ \\
\hline M2 & $3.31( \pm 0.045)^{*}$ & $4.53( \pm 0.345)$ & $3.67( \pm 0.448)^{\star} \Delta$ \\
\hline M3 & $3.27( \pm 0.073)^{*}$ & $4.27( \pm 0.360)$ & $3.53( \pm 0.294)^{\star}$ \\
\hline W1 & $3.25( \pm 0.060)^{*}$ & $4.29( \pm 0.277)$ & $3.51( \pm 0.293)^{\star}$ \\
\hline W2 & $3.28( \pm 0.067)^{*}$ & $4.48( \pm 0.358)$ & $3.69( \pm 0.365)^{\star} \Delta$ \\
\hline W3 & & \\
\hline
\end{tabular}

* Statistically significant compared to the diameter during the period of the painful stimulus. $\Delta$ Statistically significant between the group M1 compared with M3 $(P=0.033)$ and W3 in the period after stimulus $(P=0.042)$. M1 - Man without anxiety, M2 - Man with mild anxiety, M3 - man with moderate and high anxiety, and W1- women without anxiety, W2 - woman with mild anxiety, and W3 - woman with moderate and high anxiety. 
they also observed an increase in the pupil diameter in response to pain in the presence of an intact autonomic nervous system $(17,58)$. Some studies have even identified changes in the pupil response in patients with modified autonomic nervous systems, such as diabetic patients $(73,83)$ or those with manganese poisoning.

When evaluated objectively and under controlled conditions, there was no difference in the pupil response to pain between men and women, regardless of their level of anxiety, which is comparable to previous studies $(22,27,84)$.

Some studies have reported different results that show a higher average pupil diameter for women than men (17), and other studies have suggested that this difference is based on hormonal, structural, sociocultural, and emotional factors $(24,26,34,56,78)$.

Some authors found that individual factors such as age, skin color, and level of education could affect pain perception of individuals (62). These factors were not reproduced in this study.

Most studies that used subjective methods to evaluate the differences in the pain response between men and women show a higher prevalence of pain in women and find that women also have less tolerance for and greater sensitivity to pain $(12,31,55,85)$.

It is difficult to compare previous results with those obtained in this study because of the lack of previous studies that used objective methods, such as pupillometry, to compare the pain response between the genders.

Some studies have suggested that anatomical differences between male and female bodies could be responsible for some of the difference in the pain response between the genders $(27,33,86)$. However, the results of our study did not show a difference in the pain response between the genders despite a significant difference in the diameters of male and female fingers and BMI. The lack of the difference in the pain response could be explained by our use of a strong pain stimulus $(1,500 \mathrm{kPa})$ that was capable of generating a similar response in all individuals, thereby minimizing the impact of physical or structural differences.

The effect of anxiety on the perception of pain has been widely discussed in the literature, but no consensus has been reached. Some studies have suggested that the main influence of anxiety is to promote greater pain perception $(24,32,44,76)$, whereas other studies could not define the true role of anxiety in the pain process or its mode of action in the different genders (26).

The results of the present study show that the aver- age pupil diameters of individuals with moderate to severe anxiety were greater than the average diameters of those with mild or no anxiety. Additionally, men showed greater dilation than women in the presence of anxiety, although this trend was not statistically significant. The lack of significance may be the result of the sample size and requires additional studies for further clarification.

These findings lead us to believe that severe anxiety affects the pain response of an individual, regardless of gender, but with a possibly greater effect in men.

Several studies $(13,48,50,51,87)$ also demonstrated the importance of the effect of anxiety on the autonomic response in determining the nociceptive response in men and in women. Some studies observed a greater influence of anxiety in men $(24,44,50)$, especially in previous positive experiences, but they also used subjective anxiety scales.

Baker et al observed a decrease in the pupillary reflex in people of both genders who were suffering from anxiety (76); however, the papillary reflex was not evaluated in the presence of a pain stimulus.

Studies that have used pupillometry to evaluate the effects of emotional and cognitive states $(78,84,88$ 91), such as stress, deception (92), depression (93), and Alzheimer's (63), on pupillary changes have also found a strong correlation between the emotional or cognitive state and pupil diameter. However, none of these studies evaluated the role of pain.

No published studies have used pupillometry to evaluate the effect of anxiety on the nociceptive response of individuals by gender.

Because pupillometry is an objective method and is therefore measured and not only indicated, it would not be expected to be subjectively influenced by the individual because it does not require the account or consent of the individual. Pupillometry can thus be used to directly show that when anxiety is present, it physiologically alters the pain response.

It was necessary to group men with high anxiety levels with those that had moderate anxiety because the number of men with high anxiety was insufficient to create their own group. The lack of men with high levels of anxiety can perhaps be explained by a stronger association of anxiety with women $(32,48,52,94)$ and by a likely psychological and cultural disparity, wherein men handle situations differently from women. It is possible that men cannot have similar experiences to women because it might make them weak or effeminate $(54,95-97)$.

The lack of gender differences in pain perception 
shown in this study raises the question of whether differences in the response to pain stimuli occur when the response is measured objectively.

The findings of the present study lead us to propose that women and men should be treated similarly, at least in terms of pain control, by the multidisciplinary teams that manage these patients. However, regardless of gender, anxiety has been shown to modulate the pain response and to play a critical role in determining the magnitude of the pain response when the individual has a high level of anxiety. The control of anxiety must be taken into account when adequate pain management is desired, especially when anxiety levels are high, for both men and women.

Pupillometry is a noninvasive and objective measurement of the pain response that can help health care professionals who directly or indirectly deal with patients experiencing acute pain, such as intensivists, anesthesiologists, traumatologists, physiotherapists, occupational therapists, and emergency room physicians. It is possible that this method could also be used to evaluate pain in nonverbal patients, such as small children, neurological patients, and intubated patients in intensive care units, which would contribute to a better assessment and treatment. There is a clear need for a greater investment in making pupillometry more accessible so that it can be used routinely as another tool for pain assessment.

Pupillometry is an effective and objective means of assessing the pain responses of individuals with an intact autonomic nervous system, and it shows that there are no differences in the variability of this response between genders. When anxiety is present, an increase in average pupil diameter is observed that is similar for both genders, which shows that anxiety has a significant effect on pain response.

\section{Acknowledgments}

We would like to thank the Commission for Research in Ophthalmology (Comissão de Pesquisa em Oftalmologia da Ocular) - Center specializing in Ophthalmology in São Luis, Maranhão, Brazil.

\section{References}

1. Myers JE, Thompson ML, Ramushu S, Young $T$, Jeebhay MF, London L, Esswein E, Renton K, Spies A, Boulle A, Naik I, Iregren A, Rees DJ. The nervous system effects of occupational exposure on workers in a South African manganese smelter. Neurotoxicology 2003; 24:885894.

2. Fotiou F, Fountoulakis KN, Goulas A, Alexopoulos L, Palikaras A. Automated standardized pupillometry with optical method for purposes of clinical practice and research. Clin Physiol 2000; 20:336347.

3. Nèmec J, Hradil F, Wildt S. [Pupil size in $\mathrm{H}$-strain mice]. Z Versuchstierkd 1969; 11:312-319.

4. Steinhauer SR, Siegle GJ, Condray R, Pless M. Sympathetic and parasympathetic innervation of pupillary dilation during sustained processing. Int J Psychophysiol 2004; 52:77-86.

5. Wachler BS, Krueger RR. Agreement and repeatability of infrared pupillometry and the comparison method. Ophthalmology 1999; 106:319-323.

6. Wilhelm H, Wilhelm B. Clinical applications of pupillography. J Neuroophthalmol 2003; 23:42-49.

7. Boxer Wachler BS, Krueger RR. Agree- ment and repeatability of pupillometry using videokeratography and infrared devices. J Cataract Refract Surg 2000; 26:35-40.

8. Wilhelm BJ. Pupillography for the assessment of driver sleepiness. Klin Monbl Augenheilkd 2008; 225:791-798.

9. Bergamin $\mathrm{O}$, Kardon $\mathrm{RH}$. Latency of the pupil light reflex: Sample rate, stimulus intensity, and variation in normal subjects. Invest Ophthalmol Vis Sci 2003; 44:1546-1554.

10. Moresi S, Adam JJ, Rijcken J, Van Gerven PW, Kuipers $H$, Jolles J. Pupil dilation in response preparation. Int J Psychophysiol 2008; 67:124-130.

11. Wilhelm H, Neitzel J, Wilhelm B, Beuel $S$, Lüdtke $H$, Kretschmann U, Zrenner E. Pupil perimetry using $M$-sequence stimulation technique. Invest Ophthalmol Vis Sci 2000; 41:1229-1238.

12. Bush FM, Harkins SW, Harrington WG, Price DD. Analysis of gender effects on pain perception and symptom presentation in temporomandibular pain. Pain 1993; 53:73-80.

13. Elklit A, Jones A. The association between anxiety and chronic pain after whiplash injury: Gender-specific effects. Clin J Pain 2006; 22:487-49o.
14. Jones SA, Salicco JM, Byers MS. Pelvic pain and history of previous pelvic surgery. Proc Bayl Univ Med Center 2003; 16:121-122.

15. Kindler LL, Jones KD, Perrin N, Bennett RM. Risk factors predicting the development of widespread pain from chronic back or neck pain. J Pain 2010; 11:13201328.

16. Spertus IL, Burns J, Glenn B, Lofland K, McCracken L. Gender differences in associations between trauma history and adjustment among chronic pain patients. Pain 1999; 82:97-102.

17. Ellermeier W, Westphal W. Gender differences in pain ratings and pupil reactions to painful pressure stimuli. Pain 1995; 61:435-439.

18. Essick G, Guest S, Martinez E, Chen C, McGlone F. Site-dependent and subject-related variations in perioral thermal sensitivity. Somatosens Mot Res 2004; 21:159-175.

19. Fillingim RB, King $C D$, Ribeiro-Dasilva MC, Rahim-Williams B, Riley JL. Sex, gender, and pain: A review of recent clinical and experimental findings. J Pain 2009; 10:447-485.

20. Kindler LL, Sibille KT, Glover TL, Staud R, Riley JL, Fillingim RB. Drug response 
profiles to experimental pain are opioid and pain modality specific. J Pain 2011; 12:340-351.

21. Unruh AM. Gender variations in clinical pain experience. Pain 1996; 65:123-167.

22. Komiyama $\mathrm{O}$, De Laat $\mathrm{A}$. Tactile and pain thresholds in the intra- and extra-oral regions of symptom-free subjects. Pain 2005; 115:308-315.

23. Fillingim RB, Edwards RR, Powell T. The relationship of sex and clinical pain to experimental pain responses. Pain 1999; 83:419-425.

24. Frot M, Feine JS, Bushnell MC. Sex differences in pain perception and anxiety. A psychophysical study with topical capsaicin. Pain 2004; 108:230-236.

25. Grünberger J, Linzmayer L, Walter $\mathrm{H}$, Höfer C, Gutierrez-Lobos K, Stöhr H. [Assessment of experimentally-induced pain effects and their elimination by hypnosis using pupillometry studies]. Wien Med Wochenschr 1995; 145:646-650.

26. Riley JL, Robinson ME, Wise EA, Myers $C D$, Fillingim RB. Sex differences in the perception of noxious experimental stimuli: A meta-analysis. Pain 1998; 74:181-187.

27. Fillingim RB, Maixner W. The influence of resting blood pressure and gender on pain responses. Psychosom Med 1996; 58:326-332.

28. Sarlani E, Greenspan JD. Gender differences in temporal summation of mechanically evoked pain. Pain 2002; 97:163-169.

29. Greenspan JD, Craft RM, LeResche L, Arendt-Nielsen L, Berkley KJ, Fillingim RB, Gold MS, Holdcroft A, Lautenbacher S, Mayer EA, Mogil JS, Murphy AZ, Traub Rj; Consensus Working Group of the Sex Gn, and Pain SIG of the IASP. Studying sex and gender differences in pain and analgesia: A consensus report. Pain 2007; 132 Suppl 1:S26-45.

30. Kim CS, Nam KY, Kim JY. Effect of prophylactic topical brimonidine (0.15\%) administration on the development of subconjunctival hemorrhage after intravitreal injection. Retina 2011; 31:389-392.

31. al'Absi M, Buchanan TW, Marrero A, Lovallo WR. Sex differences in pain perception and cardiovascular responses in persons with parental history for hypertension. Pain 1999; 83:331-338.

32. Jones A, Zachariae R. Gender, anxiety, and experimental pain sensitivity: An overview. J Am Med Womens Assoc 2002; 57:91-94.

33. Tashani OA, Alabas OA, Johnson MI.
Cold pressor pain responses in healthy Libyans: Effect of sex/gender, anxiety, and body size. Gend Med 2010; 7:309319.

34. Myers CD, Robinson ME, Riley JL, Sheffield D. Sex, gender, and blood pressure: Contributions to experimental pain report. Psychosom Med 2001; 63:545-550.

35. Kindler LL, Valencia C, Fillingim RB, George SZ. Sex differences in experimental and clinical pain sensitivity for patients with shoulder pain. Eur ] Pain 2011; 15:118-123.

36. Riley JL, Gilbert GH, Heft MW. Orofacial pain symptom prevalence: Selective sex differences in the elderly? Pain 1998; 76:97-104.

37. Riley JL, Robinson ME, Wade JB, Myers $C D$, Price DD. Sex differences in negative emotional responses to chronic pain. J Pain 2001; 2:354-359.

38. Chen W, Woods SL, Wilkie DJ, Puntillo KA. Gender differences in symptom experiences of patients with acute coronary syndromes. J Pain Symptom Manage 2005; 30:553-562.

39. Fillingim RB, Wallace $M R$, Herbstman DM, Ribeiro-Dasilva M, Staud R. Genetic contributions to pain: A review of findings in humans. Oral Dis 2008; 14:673-682.

40. Bajaj P, Madsen H, Arendt-Nielsen L. A comparison of modality-specific somatosensory changes during menstruation in dysmenorrheic and nondysmenorrheic women. Clin J Pain 2002; 18:180190.

41. Fillingim RB, Ness TJ. Sex-related hormonal influences on pain and analgesic responses. Neurosci Biobehav Rev 2000; 24:485-501.

42. Giamberardino MA, Berkley KJ, lezzi S, de Bigontina P, Vecchiet L. Pain threshold variations in somatic wall tissues as a function of menstrual cycle, segmental site and tissue depth in non-dysmenorrheic women, dysmenorrheic women and men. Pain 1997; 71:187-197.

43. Pfleeger M, Straneva PA, Fillingim RB, Maixner W, Girdler SS. Menstrual cycle, blood pressure and ischemic pain sensitivity in women: A preliminary investigation. Int J Psychophysiol 1997; 27:161-166.

44. Janssen SA, Arntz A, Bouts S. Anxiety and pain: Epinephrine-induced hyperalgesia and attentional influences. Pain 1998; 76:309-316.

45. Jones DA, Rollman GB, White KP, Hill $M L$, Brooke RI. The relationship between cognitive appraisal, affect, and catastrophizing in patients with chronic
pain.J Pain 2003; 4:267-277.

46. Komiyama O, Kawara M, De Laat A. Ethnic differences regarding tactile and pain thresholds in the trigeminal region. J Pain 2007; 8:363-369.

47. Moldin SO, Scheftner WA, Rice JP, Nelson $E$, Knesevich MA, Akiskal H. Association between major depressive disorder and physical illness. Psychol Med 1993; 23:755-761.

48. Stewart SH, Asmundson GJ. Anxiety sensitivity and its impact on pain experiences and conditions: A state of the art. Cogn Behav Ther 2006; 35:185-188.

49. Unruh AM. Spirituality, religion, and pain. Can J Nurs Res 2007; 39:66-86.

50. Gonzalez A, Zvolensky MJ, Hogan J, McLeish AC, Weibust KS. Anxiety sensitivity and pain-related anxiety in the prediction of fear responding to bodily sensations: A laboratory test. J Psychosom Res 2011; 70:258-266.

51. Thompson T, Keogh E, French CC, Davis R. Anxiety sensitivity and pain: Generalisability across noxious stimuli. Pain 2008; 134:187-196.

52. van Wijk AJ, Hoogstraten J. Anxiety and pain during dental injections. J Dent 2009; 37:700-704.

53. Rhudy JL, Williams AE. Gender differences in pain: Do emotions play a role? Gend Med 2005; 2:208-226.

54. Barsky AJ, Peekna HM, Borus JF. Somatic symptom reporting in women and men. J Gen Intern Med 2001; 16:266-275.

55. Dao TT, LeResche L. Gender differences in pain. J Orofac Pain 2000; 14:169-184; discussion 184-195.

56. Green ML, Kraus SK, Green RG. Pupillary responses to pictures and descriptions of sex-stereotyped stimuli. Percept Mot Skills 1979; 49:759-764.

57. Hess EH, Polt JM. Pupil size as related to interest value of visual stimuli. Science 1960; 132:349-350.

58. Höfle M, Kenntner-Mabiala R, Pauli P, Alpers GW. You can see pain in the eye: Pupillometry as an index of pain intensity under different luminance conditions. Int J Psychophysiol 2008; 70:171175.

59. Harle DE, Wolffsohn JS, Evans BJ. The pupillary light reflex in migraine. Ophthalmic Physiol Opt 2005; 25:240-245.

6o. Karavanaki K, Davies AG, Hunt LP, Morgan $\mathrm{MH}$, Baum JD. Pupil size in diabetes. Arch Dis Child 1994; 71:511-515.

61. Novitskaya ES, Dean SJ, Moore JE, Moore TC, Nagendran S, Sharma A. Effects of some ophthalmic medications 
on pupil size: A literature review. Can ] Ophthalmol 2009; 44:193-197.

62. Fillingim RB. Individual differences in pain responses. Curr Rheumatol Rep 2005; 7:342-347.

63. Prettyman R, Bitsios P, Szabadi E. Altered pupillary size and darkness and light reflexes in Alzheimer's disease. J Neurol Neurosurg Psychiatry 1997; 62:665668.

64. Tryon WW. Pupillometry: A survey of sources of variation. Psychophysiology 1975; 12:90-93.

65. Yang LL, Niemann CU, Larson MD. Mechanism of pupillary reflex dilation in awake volunteers and in organ donors. Anesthesiology 2003; 99:1281-1286.

66. Fillingim RB, Edwards RR, Powell T. Sexdependent effects of reported familial pain history on recent pain complaints and experimental pain responses. Pain 2000; 86:87-94.

67. Robinson ME, Riley JL, Myers CD, Papas RK, Wise EA, Waxenberg LB, Fillingim RB. Gender role expectations of pain: Relationship to sex differences in pain. J Pain 2001; 2:251-257.

68. Khoshnood B, Mesbah $M$, Jeanbat $V$, Lafuma A, Berdeaux G. Transforming scales of measurement of visual acuity at the group level. Ophthalmic Physiol Opt 2010; 30:816-823.

69. Diet, nutrition and the prevention of chronic diseases. World Health Organ Tech Rep Ser 2003; 916:1-149.

70. Thompson CA. Eye care. Can Nurse 1947; 43:266-269.

71. Pult H, Purslow C, Murphy PJ. The relationship between clinical signs and dry eye symptoms. Eye (Lond) 2011. \{issue and pages?\}

72. Lemp MA, Bron AJ, Baudouin C, Del Castillo JM, Geffen D, Tauber J, Foulks GN, Pepose JS, Sullivan BD. Tear osmolarity in the diagnosis and management of dry eye disease. Am J Ophthal$\mathrm{mol}$ 2011. \{issue and pages?\}

73. Randall HG. What to expect at your eye exam. Diabetes Self Manag 2002; 19:810, 13-14.
74. Vena A. [Biomicroscopy of the anterior chamber. Technic of determination of the width of the camerular sinus]. Ann Ocul, Paris 1970; 203:825-826.

75. Kimura M, Koizumi MS. Teaching and learning in the physical exam: An analysis of the process by an exam of the pupils. Rev Esc Enferm USP 1993; 27:117-132.

76. Bakes A, Bradshaw CM, Szabadi E. Attenuation of the pupillary light reflex in anxious patients. $\mathrm{Br}$ J Clin Pharmacol 1990; 30:377-381.

77. Brown SM. Monocular versus binocular pupillometry. J Cataract Refract Surg 2006; 32:374-375.

78. Granholm E, Steinhauer SR. Pupillometric measures of cognitive and emotional processes. Int J Psychophysio 2004; 52:1-6.

79. Cheng AC, Rao SK, Lam DS. Correlation of infrared pupillometers and CCD camera imaging from aberrometry and videokeratography for determining scotopic pupil size. J Cataract Refract Surg 2006; 32:183-184.

8o. Periman LM, Ambrosio R, Harrison DA, Wilson SE. Correlation of pupil sizes measured with a mesopic infrared pupillometer and a photopic topographer. J Refract Surg 2003; 19:555-559.

81. Montós-Micó R, Albarrán-Diego C, Muñoz OD, Alió JL. Use of illuminance and luminance units. J Refract Surg 2004; 20:490; author reply 490.

82. Winn B, Whitaker D, Elliott DB, Phillips NJ. Factors affecting light-adapted pupil size in normal human subjects. Invest Ophthalmol Vis Sci 1994; 35:1132-1137.

83. Smith SE, Smith SA, Brown PM, Fox C, Sönksen $\mathrm{PH}$. Pupillary signs in diabetic autonomic neuropathy. Br Med J 1978; 2:924-927.

84. Girdler SS, Maixner W, Naftel HA, Stewart PW, Moretz RL, Light KC. Cigarette smoking, stress-induced analgesia and pain perception in men and women. Pain 2005; 114:372-385.

85. Soetanto AL, Chung JW, Wong TK. Are there gender differences in pain perception? J Neurosci Nurs 2006; 38:172-176.
86. al'Absi M, Wittmers LE, Ellestad D, Nordehn G, Kim SW, Kirschbaum C, Grant JE. Sex differences in pain and hypothalamic-pituitary-adrenocortical responses to opioid blockade. Psychosom Med 2004; 66:198-206.

87. Robinson ME, Wise EA, Gagnon C, Fillingim RB, Price DD. Influences of gender role and anxiety on sex differences in temporal summation of pain. J Pain 2004; 5:77-82.

88. Flade A, Lindner G. [The role of the pupil's size in the perception of other persons]. Z Exp Angew Psychol 1979; 26:436447.

89. Hicks RA, Williams SL, Ferrante F. Pupillary attributions of college students to happy and angry faces. Percept Mot Skills 1979; 48:401-402.

90. Jones QR, Moyel IS. Men's and women's affective response to photographed subjects who differ in iris-color, pupil-size and sex. Percept Mot Skills 1973; 37:483-487.

91. Rhudy JL, Williams AE, McCabe KM, Nguyen MA, Rambo P. Affective modulation of nociception at spinal and supraspinal levels. Psychophysiology 2005; 42:579-587.

92. Heilveil I. Deception and pupil size. J Clin Psychol 1976; 32:675-676.

93. Cameron OG, Abelson JL, Young EA. Anxious and depressive disorders and their comorbidity: Effect on central nervous system noradrenergic function. Biol Psychiatry 2004; 56:875-883.

94. Rhudy JL, Meagher MW. Fear and anxiety: Divergent effects on human pain thresholds. Pain 2000; 84:65-75.

95. Manson JE. Pain: Sex differences and implications for treatment. Metabolism 2010; 59:16-20.

96. Soetanto AL, Chung JW, Wong TK. Gender differences in pain perception: A signal detection theory approach. Acta Anaesthesiol Taiwan 2004; 42:15-22.

97. Fillingim RB. Sex, gender, and pain: Women and men really are different. Curr Rev Pain 2000; 4:24-30. 